\title{
Socioeconomic and environmental factors associated with malaria hotspots in the Nanoro demographic surveillance area, Burkina Faso
}

Toussaint Rouamba ${ }^{1,2,3^{*}}$ D, Seydou Nakanabo-Diallo', Karim Derra', Eli Rouamba', Adama Kazienga', Yasuko Inoue ${ }^{2,4}$, Ernest K. Ouédraogo ${ }^{5}$, Moussa Waongo ${ }^{5}$, Sokhna Dieng ${ }^{2,6}$, Abdoulaye Guindo ${ }^{2,7}$, Boukary Ouédraogo ${ }^{2,8}$, Kankoé Lévi Sallah², Seydou Barro ${ }^{9}$, Pascal Yaka ${ }^{5}$, Fati Kirakoya-Samadoulougou ${ }^{3}$, Halidou Tinto ${ }^{1}$ and Jean Gaudart ${ }^{10}$

\begin{abstract}
Background: With limited resources and spatio-temporal heterogeneity of malaria in developing countries, it is still difficult to assess the real impact of socioeconomic and environmental factors in order to set up targeted campaigns against malaria at an accurate scale. Our goal was to detect malaria hotspots in rural area and assess the extent to which household socioeconomic status and meteorological recordings may explain the occurrence and evolution of these hotspots.
\end{abstract}

Methods: Data on malaria cases from 2010 to 2014 and on socioeconomic and meteorological factors were acquired from four health facilities within the Nanoro demographic surveillance area. Statistical cross correlation was used to quantify the temporal association between weekly malaria incidence and meteorological factors. Local spatial autocorrelation analysis was performed and restricted to each transmission period using Kulldorff's elliptic spatial scan statistic. Univariate and multivariable analysis were used to assess the principal socioeconomic and meteorological determinants of malaria hotspots using a Generalized Estimating Equation (GEE) approach.

Results: Rainfall and temperature were positively and significantly associated with malaria incidence, with a lag time of 9 and 14 weeks, respectively. Spatial analysis showed a spatial autocorrelation of malaria incidence and significant hotspots which was relatively stable throughout the study period. Furthermore, low socioeconomic status households were strongly associated with malaria hotspots ( $a O R=1.21,95 \%$ confidence interval: 1.03-1.40).

Conclusion: These fine-scale findings highlight a relatively stable spatio-temporal pattern of malaria risk and indicate that social and environmental factors play an important role in malaria incidence. Integrating data on these factors into existing malaria struggle tools would help in the development of sustainable bottleneck strategies adapted to the local context for malaria control.

Keywords: Malaria, Hotspots, Spatial epidemiology, Socioeconomic status, Meteorological factors, Spatio-temporal analysis, Bottleneck strategies, Lag time

\footnotetext{
* Correspondence: rouambatoussaint@gmail.com

${ }^{1}$ Clinical Research Unit of Nanoro, Institute for Research in Health Sciences,

National Center for Scientific and Technological Research, Nanoro, Burkina

Faso

${ }^{2}$ Aix Marseille Univ, IRD, INSERM, UMR1252 Sciences Economiques \& Sociales

de la Santé \& Traitement de l'Information Médicale, Marseille, France

Full list of author information is available at the end of the article
}

(c) The Author(s). 2019 Open Access This article is distributed under the terms of the Creative Commons Attribution 4.0 International License (http://creativecommons.org/licenses/by/4.0/), which permits unrestricted use, distribution, and reproduction in any medium, provided you give appropriate credit to the original author(s) and the source, provide a link to the Creative Commons license, and indicate if changes were made. The Creative Commons Public Domain Dedication waiver (http://creativecommons.org/publicdomain/zero/1.0/) applies to the data made available in this article, unless otherwise stated. 


\section{Background}

Malaria's epidemiology is influenced by climatic factors [1-3] which affect the ecology of the vector and consequently exposure of human populations to pathogens. At a global or micro-epidemiological scale, malaria transmission is highly heterogeneous and modified by numerous factors, generating malaria hotspots that can maintain malaria transmission over a long time and across a wider area [4-7]. In 2015, according to the World Malaria Report, there were approximately 214 million cases of malaria and an estimated 438,000 deaths in malaria endemic countries, including Burkina Faso [7], with children under 5 years being the most affected [8].

In Burkina Faso, malaria is endemo-epidemic, the transmission is seasonal with a peak of incidence during and just after the rainy season and depends also on climatic and socioeconomic conditions [9]. Despite the combined efforts from local government and its international partners to mitigate the malaria burden, malaria annual incidence remains stubbornly high throughout the country areas. Additionally, the incidence of malaria increased from 309 cases per 1000 persons per year in 2011 to 514 cases per 1000 persons per year in 2016, however, the lethality due to malaria during the same period was considerably decreased (from 3.3\% in 2011 to $0.9 \%$ in 2016 or $73 \%$ of reduction) $[9,10]$. The current national policy is based on the Test-Treat-Track initiative (T3 initiative), universal distribution of long-lasting insecticide-treated nets (LLINs), seasonal malaria chemoprevention (SMC) for children under 5 years old during the high transmission period and intermittent preventive treatment (IPT) of malaria during pregnancy $[11,12]$. Beside these measures, government adopted a national policy which provided health care free-ofcharge to children under 5 years and to pregnant women attending public health facilities [13]. With these components of current national policy, it is noticeable that in 2017 and according to the national health statistics, malaria remained the first cause of outpatient consultations (43.5\%), hospitalization (clinical observation) and $(60.5 \%)$ mortality $(35.9 \%)$ in health facilities; its annual incidence was estimated at 607 cases per 1000 persons per year with a lethality rate of $0.8 \%$ in the general population [14]. These statistics provide a partial estimate of the total malaria burden because home treatment or self-medication is a common practice in the Burkinabè context $[15,16]$, and are therefore not accounted for in the statistics presented above. To overcome the high rates of morbidity and mortality related to malaria, it is crucial to undertake research to refine approaches to applying existing interventions most effectively and efficiently in local contexts, in a bottleneck approach such as malaria hotspot-targeted strategies and according to the season of transmission [3]. Albeit some studies have reported that, within a micro-epidemiological scale in endemic areas, malaria disproportionately affects population living in similar conditions (nearest mosquito breeding site, wind direction and velocity, vegetation, house construction features, human genetic and behavioural factors) [17-21], the large growing studies carried out across African countries seemed to prove that malaria hotspot-targeted approaches are efficient and have more validity $[22,23]$. However, for now the conclusion of results varied, some research have reported that malaria hotspot targeted approaches are not effective and/or efficient, especially for reducing transmission outside of the hotspot $[4,24]$.

Furthermore, albeit the effects of weather and environmental factors (social and natural) on malaria distributions at the global, regional and local scale (including the village level) are well documented [19, 25-30], controversial data regarding the role of meteorological and socioeconomic variables on generating or maintaining malaria hotspots observed at a fine scale remains a research topic to explore [17, 31-33].

In Burkina Faso, only few studies have directly or indirectly addressed spatial or spatio-temporal variation of malaria $[5,6,34]$. Some of these studies suggested relationships between malaria transmission and socioeconomic, environmental climatic variables $[5,6,17,18,34$, 35]. Nevertheless, until recently, the spatio-temporal dynamic of transmission at a fine geographical scale has not been sufficiently explored, because of lack of data. The literature investigating the role of socioeconomic and environmental factors on the dynamic spatio-temporal of malaria at the household level is growing. In such context of high malaria burden associated with national and local resource constraints in a framework of seasonal malaria chemoprevention program, we proposed to address this gap by analysing longitudinal malaria data from rural hyperendemic area in the Central-West region of Burkina Faso, Nanoro, taking into consideration socioeconomic and meteorological factors at household level.

The aim of this study was to define accurately the different transmission (or incidence) periods of malaria at a fine scale rural area and estimate the lag times between meteorological variables and high malaria incidence period. Then, to detect potential malaria spatial hotspot for each period of transmission. The study further investigated if meteorological and socioeconomic were associated to malaria hotspots observed at a fine scale over time.

\section{Methods}

\section{Study area, design and population}

The study was carried out in Nanoro Demographic Surveillance Area (DSA), located in a rural in the Central West region of Burkina Faso. DSA was created in 2009 by the Clinical Research Unit of Nanoro (CRUN) and 
covered two departments: Nanoro (15 villages) and Soaw (9 villages). The DSA lied between longitudes $1^{\circ} 892,537$ and $2^{\circ} 83,146$ West and latitudes $12^{\circ} 857,955$ and $12^{\circ}$ 872,863 North and covers an area of $594.3 \mathrm{~km}^{2}$. In this area, seven peripheral health facilities and one referral hospital (Centre Médical avec Antenne Chirurgicale, CMA) provided health care to the population. In the baseline of initial census (years 2009), 54,781 inhabitants were recorded. A unique identification number was assigned to each inhabitant of the DSA in order to track the different events occurring in the population by regular home visits [36]. This study focused on Nanoro departments health facilities (Fig. 1) [36, 37].

Our study was an observational, longitudinal cohort study. We examined all malaria cases reported in the telegram weekly official letter (Telegramme Lettre Officiel Hebdomadaire, TLOH) for 260 weeks (January 2010 to December 2014) from four health facilities of the Nanoro department $\left(406.3 \mathrm{~km}^{2}\right)$ covering 12 villages (35,952 inhabitants in 2010). The TLOH has been developed by the Burkina Faso National Epidemiological Surveillance department which provided weekly reports on 11 diseases (including malaria cases) notified in each health facility; the number of cases is then gathered and controlled by health districts each week before being sent to the Ministry of Health. All age groups patients attending health facilities within the DSA and for whom malaria diagnosis (according to national protocol) was confirmed by a parasitological exam (Rapid Diagnostic Test or Microscopy), were reported in the TLOH.

A subset from 1,028 households (Fig. 2) was further investigated, in which all individuals were included for detailed investigations, mainly for the detection of malaria hotspots and to assess the effect of socioeconomic and meteorological factors.

\section{Data acquisition procedures and data structure Malaria cases data}

Data on malaria cases were obtained from two sources. The first was extracted from TLOH of health facilities of Nanoro health district (NHD) and the second from medical consultation registries of health focal points (HFP) of CRUN. The CRUN's HFP represented sentinel health stations that were set up in the framework of health research activities and nested within each health facilities of NHD [38].

The TLOH database included all malaria cases of the study area reported by health facilities (including case

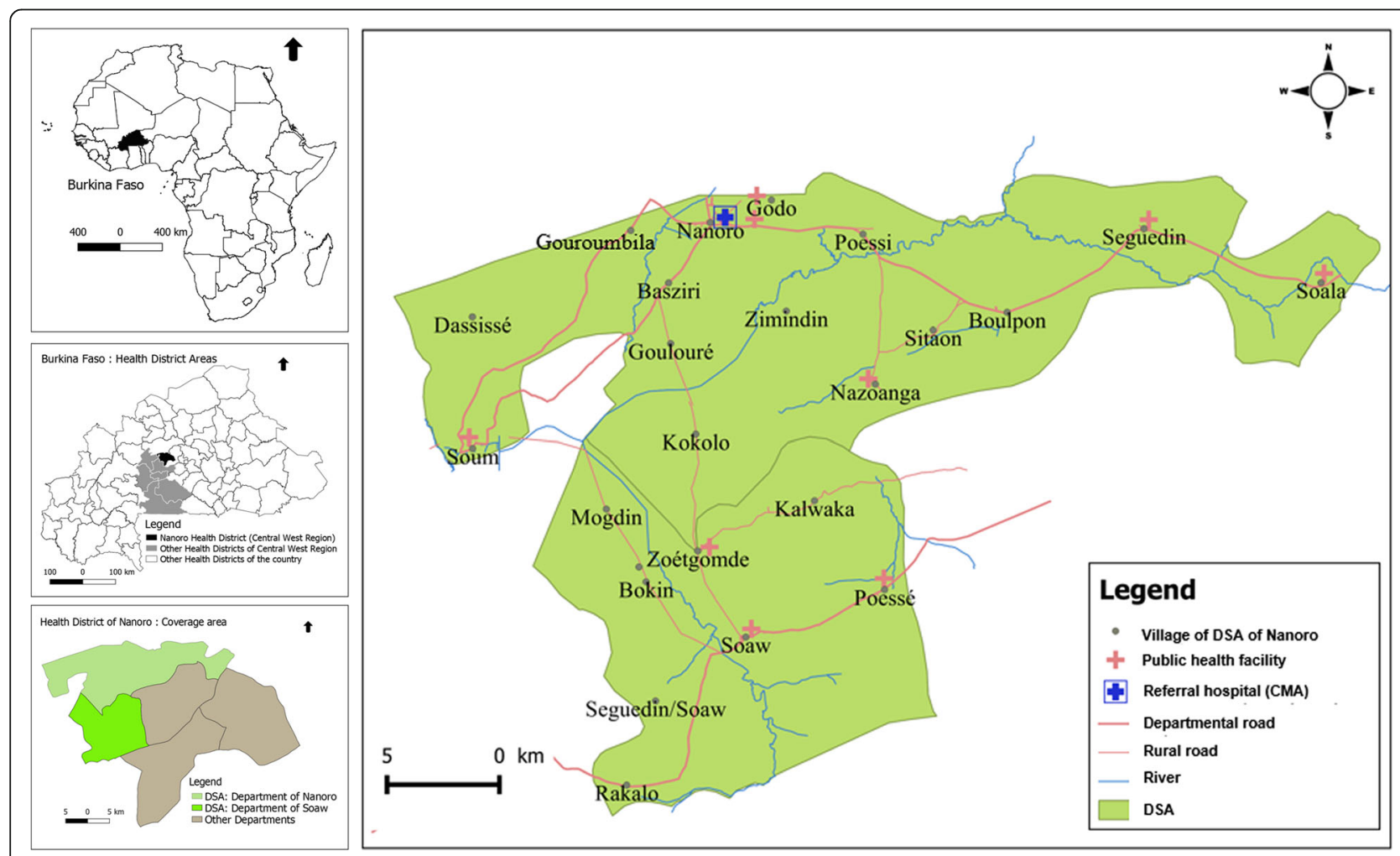

Fig. 1 Burkina Faso map showing Nanoro Health District and the Nanoro Demographic Surveillance Area (DSA). Source: Burkina Faso, Base Nationale de Découpage du territoire (BNDT, 2006); shapefile downloaded from www.maplibrary.org. Created by Eli Rouamba, 2018 


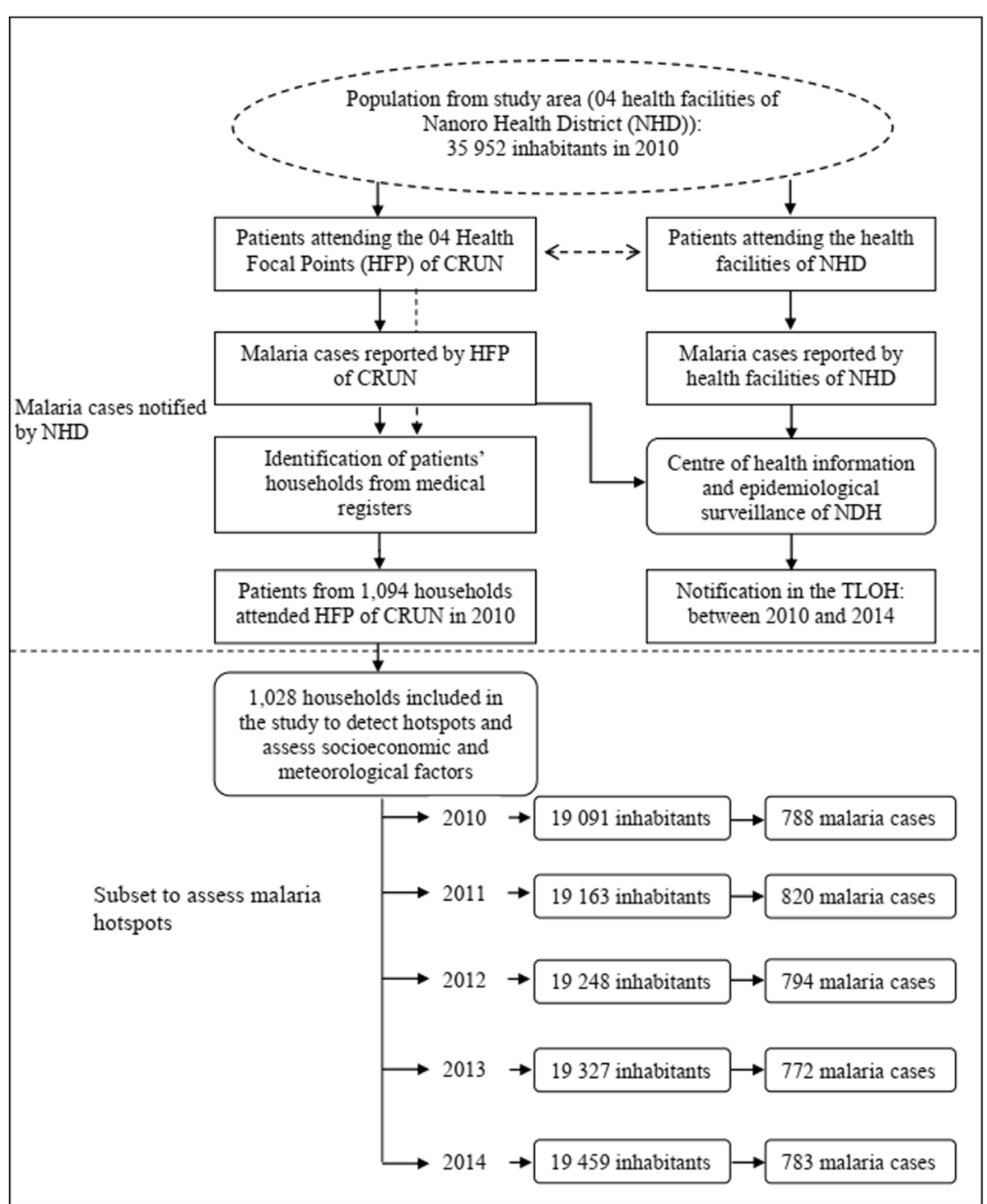

Fig. 2 Flow chart of patients and their household's selection

reported by HFP of CRUN). We extracted cases from four peripheral health facilities (Urbain, Godo, Nazoanga and Séguedin). This database aggregated malaria cases by health facility and by week (in accordance with the epidemiological calendar of the National Disease Control Directorate, Ministry of Health (Direction de Lutte contre la Maladie DLM). It was supplied by the Centre of Health Information and Epidemiological Surveillance (Centre d'Information Sanitaire et de Surveillance Epidémiologique, CISSE) of NHD.

Registries of HFP of CRUN: Each patient who was attending one of the HFP of CRUN was recorded in a registry by the medical team member who had examined him/her. Date of consultation, names, age and sex of the patient, village or neighbourhood he/she lived in, recent history of any treatment intake, weight, clinical signs, diagnosis, prescribed treatment (dose and duration) were reported.

\section{Socioeconomic, demographic and geo-location data}

This database included information from 1,028 households of individuals of HFP registries. All participants provided their consent to be part to a Health and Demographic Surveillance System (HDSS). Socioeconomic, demographic and Geo-location data were extracted from DSA database of CRUN. A unique identification number hold by each permanent resident [36] allowed us to establish the link between of individuals in the registries through a HDSS to their respective houses. Data on 26 variables of individual demography, household possessions and assets and materials for house construction were extracted. For this present study, analysis has been 
conducted at household level, so the individual data have not been considered.

Data on household included number of inhabitants per household, water source, house types and shapes, main goods and properties (for further precisions see [36]).

Geo-location data for each household was provided by GPS (Global Positioning System coordinates). These geolocation data were collected as part of the HDSS [36].

\section{Meteorological data}

These data were collected by the National Meteorological Directorate (Direction Générale de la Metéorologie, DGM), and aggregated weekly in accordance to the epidemiological calendar.

The data from local rainfall station located in Nanoro was used. Since temperature and humidity data were not available at departmental level, data from the synoptic station of Ouagadougou, located at about $85 \mathrm{~km}$ from the study area, were used, in accordance with the standards of the World Meteorological Organization (WMO). Thus, for evapotranspiration and temperature, WMO recommends a maximum distance of $150 \mathrm{~km}$ between the measuring stations. For the rainfall network, WMO recommends a minimum of one station per $10,000 \mathrm{~km}^{2}$ area [39]. The selected meteorological variables were rainfall (cumulative rainfall and number of rain events per week); temperatures (average of minimum and maximum per week, total average per week); relative humidity (minimum and maximum average per week, total average per week).

\section{Geographical data}

Nanoro department shape file (administrative boundary) with UTM zone 30 projection (Universal Transverse Mercator coordinate system zone 30) was downloaded from the following website: www.maplibrary.org.

\section{Statistical analysis \\ Descriptive and exploratory analysis of time series}

Malaria incidence per week was estimated providing time series. Mann-Kendall test $[40,41]$ was used to assess the trend of the time series. The periodicities of the time series were assessed by their autocorrelograms, following the Box-Jenkins approach [42].

To take into account combinations of meteorological variables, but also to solve the collinearity and to reduce dimension, a principal component analysis (PCA) [43] was used, and the number of dimensions were selected according to the Kaiser rule.

To define transmission periods we performed, after a logarithmic transformation of the malaria incidence, a change point analysis [44], in order to detect significant changes in the mean and variance of the series for 260 weeks. For this purpose, the algorithm PELT (Pruned
Exact Linear Time) [45] was used and the Modified Bayesian Information Criterion [46] was chosen for penalty.

\section{Building ARIMA seasonal model and cross-correlation of the malaria series with the series of meteorological variables}

Box-Jenkins approach [42] was used to model independently each time series. The best seasonal autoregressive integrated moving average (SARIMA) model was selected with the lowest Akaike Information Criterion (AIC). The remaining white noise was verified by using the LjungBox and Student test. With this approach, stationary time series were obtained, and used to explore relationships between time series.

Cross correlation function (CCF) was then used to assess the relationship between weekly meteorological variables (principal components), and log-transformed weekly malaria incidence.

\section{Spatio-temporal analysis for hotspots detection}

In our study a hotspot was defined using Martin Kulldorff's Satscan approach [47] and was defined as statistical cluster or area of houses aggregation where malaria or incidence is higher than in the surrounding areas [4]. Spatial analysis for local hotspots detection was performed by using a purely elliptic spatial analysis (Poisson distribution), the detection was performed in each of the three combined period of malaria transmission (results of the change point analysis) in order to limit the impact of very high risk cluster on secondary cluster detection $[48,49]$. The $p$-values were estimated by Monte Carlo inference.

Location of all household and statistically significant hotspots were mapped and roads, land, permanent water bodies were added using information from OpenStreetMap, after geo-referencing (https://www.openstreetmap.org/\#map=12/12.6228/-2.1622).

\section{Multivariable analysis}

Based on Kulldorff scan detection results, the outcome variable was categorized as "being in a significant hotspot" (1) and "not being in a significant hotspot" (0) throughout the different transmission periods. Socioeconomic profile of each household and the effect of this profile on malaria hotspot were established by proceeding as follow. Firstly, we performed Multiple Correspondence Analysis (MCA) including all socioeconomic and demographic variables. The resulted coordinates (from the MCA) were then used for a hierarchical ascendant classification [50]. The end result grouped all the households in three clusters or "socioeconomic profiles". Secondly, we used generalized estimating equations (GEE) model to explore the effect of socioeconomic profiles and principal components (by considering lag times between meteorological variables variable and high malaria transmission period) on malaria 
hotspot across time (malaria transmission periods). The accurate working correlation matrix was selected by assessing the correlation structure showing the low QIC (Quasi-AIC) score [51].

\section{Ethics consideration}

This analysis used household socioeconomic data from Nanoro HDSS that set up a population-based monitoring system in a framework of main study entitle 'Pharmacovigilance for ACTs in Africa' and was approved by Centre Muraz Institutional Ethical Committee $\left(\mathrm{N}^{\circ}\right.$ Réf. 03-2010C/E-CM), Burkina Faso National Ethics Committee for Research in Health (N $2010-27)$.

\section{Software and packages}

Statistical analyses were performed using the $\mathrm{R}$ software version 3.2.5 ( $\mathrm{R}$ Development Core Team, R Foundation for Statistical Computing, Vienna, Austria), including the following packages: autoarima, Dcluster, FactoMineR, geepack, rgdal. Local hotspot assessment was performed by using the SatScan ${ }^{\mathrm{Tm}}$ software version 9.4.2. Maps were provided by using the QGIS software (2014 QGIS Development Team).

\section{Results}

\section{Description of time series and subset characteristics}

Over the 5 years, 115,306 malaria cases were notified in the TLOH. The annual malaria incidence per 1000 inhabitants were 559,581, 613, 646 and 623 respectively for year 2010, 2011, 2012, 2013 and 2014. For the subset, 19,091 subjects from 1,028 households were included in 2010, among them 788 malaria cases were reported. The flow of the study subject selection is shown on Fig. 2.

The Fig. 3 which illustrates the evolution of malaria incidence and meteorological variables time series, showed a maximum peak every 52 week, indicating the classical seasonal pattern of this endemo-epidemic area, but no trend was observed (see Additional file 1).

The reduction of meteorological variables showed that the two first components explained $88.25 \%$ of the total inertia (see Additional file 2). The first component was mainly associated to rainfall (cumulative rainfall and number of rain events) and relative humidity (maximum, minimum and average). The second component was mainly associated to temperatures (maximum, minimum and average).

The cross-correlation analysis between malaria and the first component showed that rainfall and humidity were positively and significantly associated with malaria incidences with a time lag of 9 weeks. The lag time of 9 weeks indicates the time elapsing periods between the peak of rainfalls and the peak of malaria incidence (rise of malaria case). The second component showed that temperatures were positively and significantly associated with malaria cases with a time lag of 14 weeks. The time lagged variables were used in the GEE regression for components 1 and 2 in order to assess the impact of these meteorological factors on spatial hotspot genesis.

The change point analysis of the malaria time series identified 15 time-points or periods. These periods were uniformly distributed annually (three periods each year). The most important changes in the time series for malaria incidence for one period (i.e. 52 weeks) occurred between July and mid-November where malaria incidences increased (about 3.53-fold) (Table 1 and Fig. 3).

\section{Spatio-temporal hotspot detection}

Kulldorff scan method for hotspots detection, according to the three transmission periods, showed a spatio-temporal heterogeneity. But, the location of the different hotspots through the study area was relatively stable through the study period. Two significant hotspots were detected during the low and intermediate transmission periods, with relative risks (RR) of 2.15 and 3.69 (Low transmission period, respectively 82 and 13 households, $p<0.001$ ), and of 1.50 and 1.94 (Intermediate transmission period, respectively 211 and 43 households, $p=0.001$ and $p=$ 0.028). Five significant hotspots were identified during the high transmission period. Principally, this area belonged to the villages of Gouroumbila, Nanoro, Basziri, Goulouré and Godo. The hotspot which showing the highest RR was in Séguedin village $(\mathrm{RR}=6.90,1$ single household, $p$ $=0.002$ ). The largest hotspot counted 255 households, with the lowest RR of $1.30(p=0.011)$ and was located both in Nanoro and Godo Villages (Table 2, Fig. 4, and Additional file 3).

\section{Multivariable analysis}

In this study area, we find three socioeconomic profiles among the 1,028 households. Thus, 797 (77.5\%), 219 (21.3\%) and $12(1.2 \%)$ households were classified (from HCA) as low, middle and high socioeconomic status respectively (Table 3 ). The low socioeconomic class was characterized mainly by a shorter distance to health facility $(37.8 \%)$, less material goods ownership (excluding mobile phone, $89.7 \%$, radio, $69.6 \%$ ), less latrines (2.8\%), piped water, no electricity and no gas, more houses made by clay bricks, dirty floors, and clay, wood, or straw made roofs.

Unadjusted univariate GEE analysis (Table 4) revealed significant associations between malaria hotspots and households classified as low socioeconomic status (OR = 1.23, 95\% CI: $1.05-1.44$ and the temperature component (OR $=0.65,95 \%$ CI: 0.61-0.69). After adjusting on temperature and rainfall/humidity, households showing a low socioeconomic status presented the highest significant risk ( $\mathrm{aOR}=1.21,95 \% \mathrm{CI}: 1.03-1.40)$ associated to malaria hotspot compared to the households belonging to the medium and high status. 


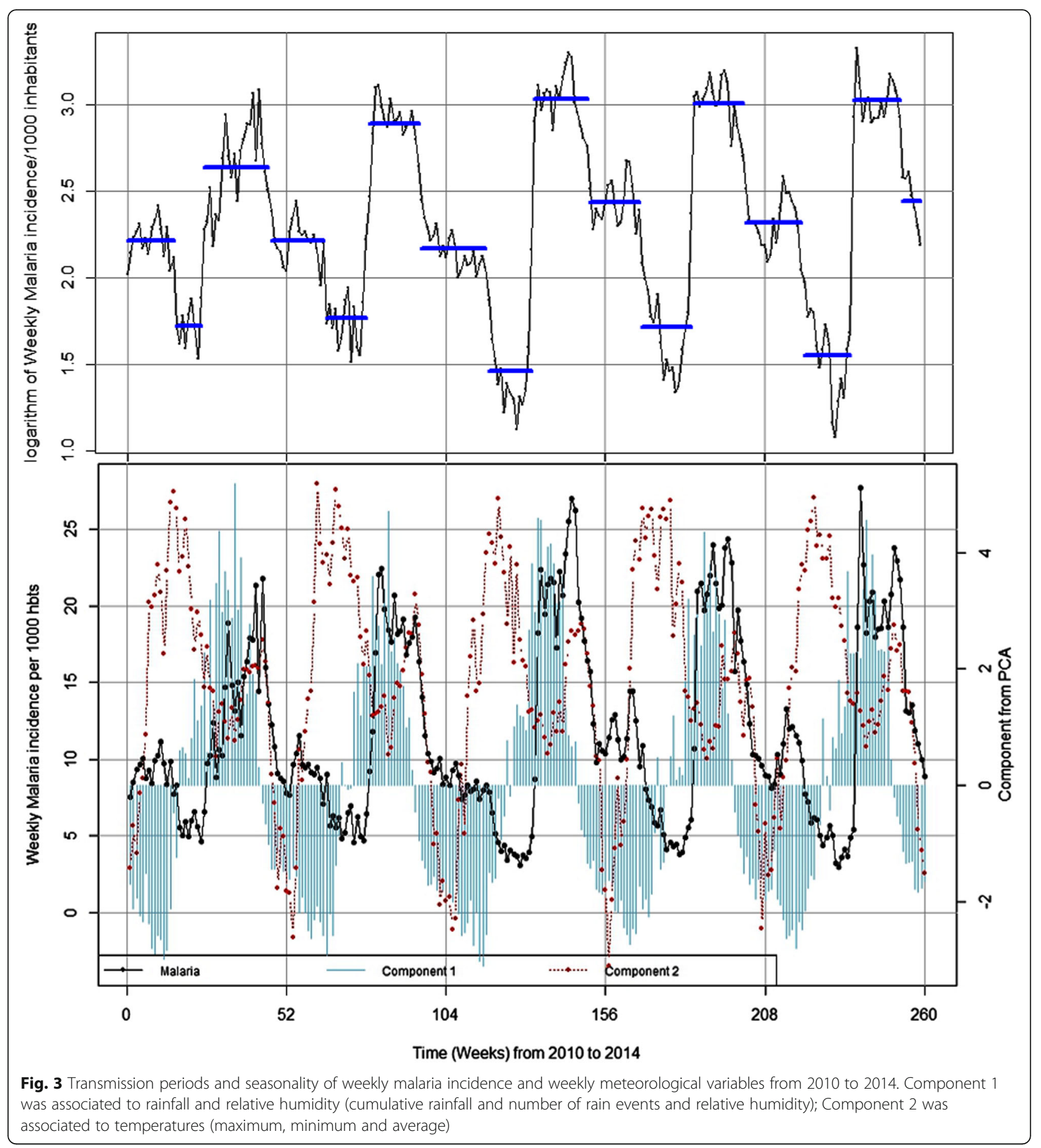

\section{Discussion}

This longitudinal observational study showed the annual seasonal pattern of malaria incidence, but with an intermediate transmission (or incidence) period between the two-classical low and high transmission. Moreover, weekly rainfall was positively associated with weekly malaria incidence, with a lag time of 9 weeks. Our findings supported a relative stability of the spatio-temporal pattern. The relative stable hotspots were associated with meteorological factors but also with low socioeconomic status.

Contrary to literature that describes two malaria transmission periods (high and low) in Burkina Faso [17, 37], our results have shown three clear transmission (or incidence) periods per year in Nanoro setting which correspond to high, intermediate and low period of malaria 
Table 1 Description of malaria incidence and rainfall according to the transmission periods

\begin{tabular}{|c|c|c|c|c|c|c|}
\hline Year & Seasons & Start date & Seasons Duration ${ }^{a}$ & Incidence $^{\mathrm{b}}$ & Rainfall $^{c}$ & Rainfall with lagd \\
\hline \multirow[t]{4}{*}{2010} & Intermediate & 2010-01-04 & 16 & 9.18 & 0.82 & 10.38 \\
\hline & Low & $2010-04-26$ & 9 & 5.64 & 16.99 & 37.32 \\
\hline & high & $2010-06-28$ & 22 & 14.40 & 28.13 & 12.86 \\
\hline & Intermediate & 2010-11-29 & 18 & 9.20 & 0 & 6.18 \\
\hline \multirow[t]{3}{*}{2011} & Low & 2011-04-04 & 14 & 5.95 & 18.36 & 34.61 \\
\hline & high & 2011-07-11 & 17 & 18.08 & 21.99 & 2.06 \\
\hline & Intermediate & 2011-11-07 & 22 & 8.78 & 0 & 5.69 \\
\hline \multirow[t]{3}{*}{2012} & Low & 2012-04-09 & 15 & 4.49 & 19.69 & 47.05 \\
\hline & high & $2012-07-23$ & 18 & 20.91 & 31.22 & 1.47 \\
\hline & Intermediate & $2012-11-25$ & 17 & 11.50 & 0 & 6.30 \\
\hline \multirow[t]{3}{*}{2013} & Low & 2013-03-25 & 17 & 5.76 & 15.03 & 29.96 \\
\hline & high & $2013-07-22$ & 17 & 20.32 & 25.69 & 4.64 \\
\hline & Intermediate & 2013-11-18 & 19 & 10.24 & 0.16 & 5.81 \\
\hline \multirow[t]{3}{*}{2014} & Low & 2014-03-31 & 16 & 4.88 & 19.18 & 32.36 \\
\hline & high & $2014-07-21$ & 16 & 20.64 & 23.7 & 3.62 \\
\hline & Intermediate & 2014-11-10 & 7 & 11.63 & 0 & 0 \\
\hline
\end{tabular}

${ }^{\mathrm{a}}$ Seasons Duration in weeks

${ }^{\mathrm{b}}$ Malaria incidence per 1000 person-weeks for the transmission season

${ }^{c}$ Accumulates Rainfall $(\mathrm{mm}) /$ week for the same transmission season

${ }^{\mathrm{d} A c c u m u l a t e s}$ Rainfall $(\mathrm{mm})$ / week with time lag (9 weeks)

incidence. Similar result was recently found by Ouedraogo et al. (2018) in Ouagadougou. Our intermediate period of malaria incidence (middle-November to March) is consistent with the rainfall transition period reported in the literature (November and February) [37]. During our "intermediate" period, recorded rainfalls were quasi null (Table 1), however, the presence of wetlands (temporary and permanent waterbodies) associated with optimum range of temperatures $\left(28.41^{\circ} \mathrm{C}\left[18^{\circ}-38^{\circ}\right]\right)$, relative humidity (30.33\% [12-47\%]), and human activities (off-season agriculture is intensifying during this period) created suitable conditions to maintain larval or mosquito abundance and thus contributed to maintain risk for malaria transmission in human populations.

Furthermore, considering the lag time ( 9 weeks) found in our study, rainfalls had a delayed influence on malaria cases whatever the transmission period (Table 1). These findings established the classical positive strong temporal association between meteorological factors (component 1: rainfall \& relative humidity; and component 2: temperatures) and weekly malaria incidence in our area. In addition, these lag times coincided with the theoretical

Table 2 Malaria hotspots detected by the elliptic scan

\begin{tabular}{|c|c|c|c|c|c|c|c|}
\hline Period & $\mathrm{N}^{\mathrm{a}}$ & $x^{b}$ & $Y^{b}$ & Axis in km (major/minor) & Number of households & $\mathrm{RR}^{\mathrm{c}}$ & $P$ value \\
\hline \multirow[t]{5}{*}{$\operatorname{High}^{H}$} & 1 & 595,099 & $1,395,750$ & 1.09/1.09 & 38 & 1.84 & $<0.001$ \\
\hline & 2 & 604,229 & $1,401,150$ & $0.00 / 0.00$ & 1 & 6.90 & 0.002 \\
\hline & 3 & 614,102 & $1,400,450$ & $1.12 / 0.56$ & 12 & 2.27 & 0.003 \\
\hline & 4 & 587,828 & $1,403,520$ & $6.01 / 2.00$ & 255 & 1.30 & 0.011 \\
\hline & 5 & 598,740 & $1,399,110$ & $0.31 / 0.15$ & 2 & 4.90 & 0.015 \\
\hline \multirow[t]{2}{*}{ Inter' $^{\prime}$} & 1 & 586,028 & $1,400,300$ & $3.28 / 3.28$ & 211 & 1.50 & 0.001 \\
\hline & 2 & 611,969 & $1,397,070$ & $7.09 / 2.36$ & 43 & 1.94 & 0.028 \\
\hline \multirow[t]{2}{*}{ Low $^{L}$} & 1 & 595,715 & $1,395,570$ & $2.67 / 1.78$ & 82 & 2.15 & $<0.001$ \\
\hline & 2 & 581,892 & $1,401,070$ & $1.82 / 0.61$ & 13 & 3.69 & $<0.001$ \\
\hline
\end{tabular}

L Low transmission periods

I intermediate transmission periods

$H$ high transmission periods

${ }^{a}$ Number of hotspots for each period

${ }^{b}$ Centroid coordinates of hotspots (UTM zone 30 )

${ }^{c} R R$ (Relative risk) 


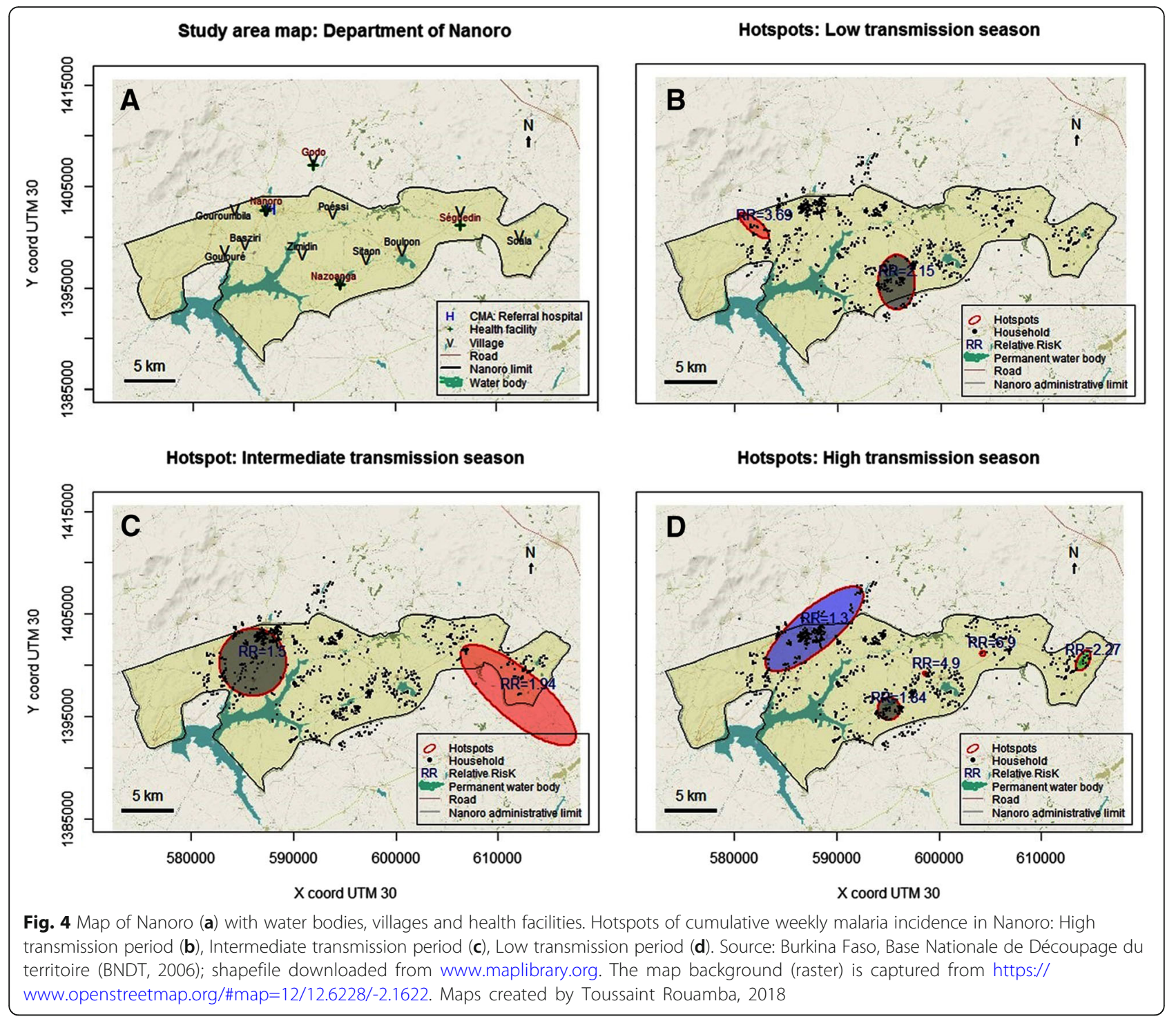

vector-parasite-host cycle under optimum conditions [5255] and contributes to better understanding the classical hypothesis of biological/ecological drivers of the spatialtemporal distribution of malaria throughout a country. Indeed, surface water from first rainfalls may have been rapidly dried, by infiltration or evaporation. Therefore, the formation of a temporary waterbodies needed numerous rainfalls before becoming breeding sites. Another delay may be due to the vector life cycle itself, from eggs to adults, and the number of cycles before reaching the sufficient population needed to accelerating the parasite transmission (also depending on meteorological factors favouring mosquito survival). Finally, another delay may be observed until the first clinical cases were reported, defining the epidemic "official" onset.

In Ghana [56], neighbouring country of Burkina, in Ethiopia (East Africa) and China [1, 57-59], rainfalls and malaria were positively correlated with a lag time of 9 and 10 weeks respectively. Similarly, lag times between one and 3 months were reported in Mali (3 months), Kenya (one and 3 months) and China (1 month) $[58,60,61]$. By contrast, malaria incidence rate was delayed by 2 weeks compared to meteorological factors in Ouagadougou, located at about $85 \mathrm{~km}$ from Nanoro site. According to the authors of this latter study, the 5 dams located in this central region may contribute to the constant presence of vectors, which explains this short delay [6]. Taken together, this finding highlights the variability of spatio-temporal dynamic of malaria at micro-epidemiological scale in endemic areas. These lag times should be understood and considered by the Health Program Planners when implementing SMC campaigns in local context for delivering interventions at the right/relevant time. 
Table 3 Socioeconomic characteristics of households (1028) obtained by the hierarchical ascendant classification

\begin{tabular}{|c|c|c|c|c|}
\hline & \multicolumn{4}{|c|}{ Socioeconomic status of households } \\
\hline & $\begin{array}{l}\text { Low } \\
N=797\end{array}$ & $\begin{array}{l}\text { Middle } \\
N=219\end{array}$ & $\begin{array}{l}\text { High } \\
N=12\end{array}$ & $\begin{array}{l}\text { Total } \\
N=1028\end{array}$ \\
\hline \multicolumn{5}{|c|}{ Distance to health facility, n (\%) } \\
\hline$<5 \mathrm{~km}$ & $540(67.8)$ & $127(58.0)$ & $5(41.7)$ & $672(65.4)$ \\
\hline $5-10 \mathrm{~km}$ & $251(31.5)$ & $87(39.7)$ & $7(58.3)$ & $345(33.6)$ \\
\hline$>10 \mathrm{~km}$ & $6(0.8)$ & $5(2.3)$ & $0(0)$ & $11(1.1)$ \\
\hline \multicolumn{5}{|l|}{ Ownership of radio, n (\%) } \\
\hline No & $242(30.4)$ & $38(17.4)$ & $4(33.3)$ & $284(27.6)$ \\
\hline Yes & $555(69.6)$ & $181(82.6)$ & $8(66.7)$ & $744(72.4)$ \\
\hline \multicolumn{5}{|l|}{ Ownership of TV, n (\%) } \\
\hline No & $788(98.9)$ & 159 (72.6) & $0(0)$ & $947(92.1)$ \\
\hline Yes & $9(1.1)$ & $60(27.4)$ & $12(100)$ & $81(7.9)$ \\
\hline \multicolumn{5}{|c|}{ Ownership of mobile phone, n (\%) } \\
\hline No & $82(10.3)$ & $4(1.8)$ & $0(0)$ & $86(8.4)$ \\
\hline Yes & $715(89.7)$ & $215(98.2)$ & $12(100)$ & $942(91.6)$ \\
\hline \multicolumn{5}{|l|}{ Ownership of fridge, n (\%) } \\
\hline No & $797(100)$ & $206(94.1)$ & $0(0)$ & $1003(97.6)$ \\
\hline Yes & $0(0)$ & $13(5.9)$ & $12(100)$ & $25(2.4)$ \\
\hline \multicolumn{5}{|l|}{ Ownership of car, n (\%) } \\
\hline No & 796 (99.9) & $199(90.9)$ & $8(66.7)$ & $1003(97.6)$ \\
\hline Yes & $1(0.1)$ & $20(9.1)$ & $4(33.3)$ & $25(2.4)$ \\
\hline \multicolumn{5}{|c|}{ Ownership of motorcycle, n (\%) } \\
\hline No & $322(40.4)$ & $47(21.5)$ & $0(0)$ & $369(35.9)$ \\
\hline Yes & $475(59.6)$ & $172(78.5)$ & $12(100)$ & $659(64.1)$ \\
\hline \multicolumn{5}{|l|}{ Ownership of bicycle, n (\%) } \\
\hline No & $14(1.8)$ & $10(4.6)$ & $1(8.3)$ & $25(2.4)$ \\
\hline Yes & $783(98.2)$ & $209(95.4)$ & $11(91.7)$ & $1003(97.6)$ \\
\hline \multicolumn{5}{|l|}{ Toilet ownership, n (\%) } \\
\hline Latrine & $3(0.4)$ & $66(30.1)$ & $11(91.7)$ & $80(7.8)$ \\
\hline Latrines unenriched & $19(2.4)$ & $151(68.9)$ & $1(8.3)$ & $171(16.6)$ \\
\hline Absence & $775(97.2)$ & $2(0.9)$ & $0(0)$ & 777 (75.6) \\
\hline \multicolumn{5}{|c|}{ Major source of drinking water, n (\%) } \\
\hline Tap (Piped water) & $2(0.3)$ & $6(2.7)$ & $7(58.3)$ & $15(1.5)$ \\
\hline Well & $131(16.4)$ & $1(0.5)$ & $0(0)$ & $132(12.8)$ \\
\hline Water drilling & $660(82.8)$ & $212(96.8)$ & $1(8.3)$ & $873(84.9)$ \\
\hline Other & $4(0.5)$ & $0(0)$ & $4(33.3)$ & $8(0.8)$ \\
\hline \multicolumn{5}{|l|}{ Main source of lighting, n (\%) } \\
\hline Electricity & $0(0)$ & $89(40.6)$ & $12(100)$ & $101(9.8)$ \\
\hline Other & $797(100)$ & $130(59.4)$ & $0(0)$ & $927(90.2)$ \\
\hline \multicolumn{5}{|c|}{ Main material of walls (bedrooms), n (\%) } \\
\hline Made of cement bricks & $7(0.9)$ & $59(26.9)$ & $11(91.7)$ & $77(7.5)$ \\
\hline Semi-hard & $81(10.2)$ & $12(5.5)$ & $1(8.3)$ & $94(9.1)$ \\
\hline Made of clay bricks & $709(89.0)$ & $148(67.6)$ & $0(0)$ & $857(83.4)$ \\
\hline
\end{tabular}


Table 3 Socioeconomic characteristics of households (1028) obtained by the hierarchical ascendant classification (Continued)

\begin{tabular}{|c|c|c|c|c|}
\hline & \multicolumn{4}{|c|}{ Socioeconomic status of households } \\
\hline & $\begin{array}{l}\text { Low } \\
N=797\end{array}$ & $\begin{array}{l}\text { Middle } \\
N=219\end{array}$ & $\begin{array}{l}\text { High } \\
N=12\end{array}$ & $\begin{array}{l}\text { Total } \\
N=1028\end{array}$ \\
\hline \multicolumn{5}{|l|}{ Main material of the floor, $\mathrm{n}(\%)$} \\
\hline Tiles & $0(0)$ & $0(0)$ & $4(33.3)$ & $4(0.4)$ \\
\hline Cover floor with roughcast (cement) & $568(71.3)$ & $216(98.6)$ & $8(66.7)$ & $792(77.0)$ \\
\hline Dirt floor & $229(28.7)$ & $3(1.4)$ & $0(0)$ & $232(22.6)$ \\
\hline \multicolumn{5}{|l|}{ Main material of the roof, $\mathrm{n}(\%)$} \\
\hline With iron sheets & $720(90.3)$ & $219(100)$ & $12(100)$ & $951(92.5)$ \\
\hline Made of clay and wood & $64(8.0)$ & $0(0)$ & $0(0)$ & $64(6.2)$ \\
\hline Made of straw and wood & $13(1.6)$ & $0(0)$ & $0(0)$ & $13(1.3)$ \\
\hline \multicolumn{5}{|l|}{ Gas for cooking, n (\%) } \\
\hline No & $797(100)$ & $216(98.6)$ & $4(33.3)$ & $1017(98.9)$ \\
\hline Yes & $0(0)$ & $3(1.4)$ & $8(66.7)$ & $11(1.1)$ \\
\hline \multicolumn{5}{|l|}{ Electricity, n (\%) } \\
\hline No & $797(100)$ & $130(59.4)$ & $0(0)$ & $927(90.2)$ \\
\hline Yes & $0(0)$ & 89 (40.6) & $12(100)$ & $101(9.8)$ \\
\hline
\end{tabular}

However, studies carried out in Sri Lanka and Madhya Pradesh (Central India), did not detect a clear relationship between rainfall and malaria incidence probably because of dry areas [62] or flooded areas [63].

Our study area was characterised by a spatial aggregation and spatio-temporal heterogeneity of malaria cases through all transmission periods. Similarly, in Burkina Faso, a study that use the Kulldorff's approach with health facility as spatial scale, had found also a spatial variability and relative temporal stability of malaria incidence around the capital Ouagadougou [6].

The persistence of hotspots, especially in the village of Nanoro (down-town of the department) and its surrounding, could be explained partly by several combined factors. First, by presence of several areas of off-season agriculture, better health services accessibility that could improve

Table 4 Factors associated with malaria hotspots

\begin{tabular}{|c|c|c|c|c|}
\hline & \multicolumn{2}{|l|}{ Univariate } & \multicolumn{2}{|l|}{ Multivariable } \\
\hline & OR [95\% Cl] & $P$ value & $\mathrm{aOR}[95 \% \mathrm{Cl}]$ & $P$ value \\
\hline \multicolumn{5}{|c|}{ Socioeconomic status } \\
\hline Medium (Ref) & 1 & - & 1 & - \\
\hline Low & $1.23[1.05-1.44]$ & $0.013^{b}$ & $1.21[1.03-1.40]$ & $0.021^{b}$ \\
\hline High & 0.90 [0.43-1.92] & 0.79 & $0.93[0.43-1.98]$ & 0.84 \\
\hline Component 1 & $1.03[1.00-1.06]$ & $0.05^{\mathbf{a}}$ & $1.01[0.97-1.05]$ & 0.68 \\
\hline Component 2 & $0.65[0.61-0.69]$ & $<0.001^{\mathrm{c}}$ & $0.65[0.61-0.69]$ & $<0.001^{\mathrm{C}}$ \\
\hline
\end{tabular}

Component 1: resumed rainfalls considering its lag time with malaria

Component 2: resumed temperatures considering its lag time with malaria $a O R$ adjusted odds ratio

${ }^{a}$ significant at the 0.1 leve

${ }^{b}$ significant at the 0.05 level

csignificant at the 0.01 level malaria cases reporting, the construction of the new dam of Soum which created a swampy area, favourable conditions for the breeding sites. Second, by the high population density which was estimated at 104 persons per $\mathrm{km}^{2}$ [36]. However, it is important to note that this relationship may not be linear nor direct. Indeed, study carried-out in malaria endemic countries across Africa suggested that population densities of 100 persons per $\mathrm{km}^{2}$ were more predictive of malaria infection in young children than very low densities (less than 10 persons per $\mathrm{km}^{2}$ ) or very high densities (more than 1000 persons per $\mathrm{km}^{2}$ ) [64]. Another study in Ethiopian highland suggests that, the spatial distribution of malaria in the low season is well-explained by both temperature and population density [65].

Persistence of malaria hotspots during low transmission periods might constitute a stepping-stone control strategies, and stir transmission during high transmission periods [22]. Therefore, these hotspots in low transmission seasons could be targeted for efficacious strategies, following a bottleneck approach to reduce malaria transmission at the local scale (see Additional file 3) $[4,66]$.

Our findings regarding the space-time dynamic of malaria, the three incidence periods of malaria and the lag time elapsing periods between the peak of rainfalls and the peak of malaria incidence might be considered for disrupting malaria transmission in the study area by adapting the malaria SMC program to local context and developing bottleneck strategies. Indeed, new strategies such as mass drug administration (MDA), mass screening and treatment (MSAT) are under consideration [23].

This study also found that malaria hotspots were constituted by all types of households whatever their 
socioeconomic status, this emphasizes that vector breeding sites were common in this area and the behaviour of the majority population influenced the profile and intensity of malaria transmission. Nevertheless, within this setting, low socioeconomic status of households and meteorological factors were positively correlated with malaria hotspots. After adjusting for meteorological components, the association of low socioeconomic status with malaria hotspots still remained. Poorer socioeconomic status of households was significantly associated with some factors that lead to increase and sustain malaria transmission, from poor-quality housing (bedroom with clay brick walls, roof made of clay/straw and wood, dirt floor, absence electricity, and absent of toilet, absence of tap) and absence of exposure to TV prevention campaigns. This positive association between malaria transmission and low socioeconomic status has been previously described in Burkina Faso at national or sub-national level [5, 17, 18, 34, 67].

The association with the rainfall/humidity disappeared in the multivariable analysis. Possible explanations of this observation could be inter alia, (1) the location of the households near water points, (2) permanent waterbodies due to the construction of the new dam of Soum which created flooded areas.

One limitation of the study was the fact that the study included both malaria cases diagnosed actively and passively. The passive detection of malaria cases might bias the findings by people who live closer to a health facility. However, this bias could be considered low because, in our context, about two-thirds of the study participant houses were located less than five kilometres. Moreover, active case detection, even in remote areas from health facilities, have also limited a potential bias due to health facility proximity. Additionally, as prevalence of home or self-treatment was presumably high, malaria incidence may be underestimate. A study carried out in 2011 noted that $72.7 \%$ of presumptive malaria admitted in a hospital of district practiced self-medication at home [68]. However, in our study area, strategies have been implemented to limit the practice of self-medication. Indeed, DSA's field workers and community-based health workers, permanently sensitized population to avoid self-medication and attend a health facility if they experienced abnormal symptoms.

\section{Conclusion}

Our study area was characterized by high incidence of malaria despite increasing efforts to fight the disease during the last decade. Findings showed a clear annual seasonal pattern of malaria incidence with three periods of different level of incidence and determined the lag times ( 9 weeks) between suitable meteorological factors and the peak of incidence of malaria. At a fine scale, and according to the three periods of malaria incidence, our findings supports a relative spatio-temporal stability of malaria hotspots, which were characterized by low socioeconomic status. Understanding environmental and socio-economic factors associated to the spatio-temporal dynamic of malaria is of high importance to adapt current control strategies and to develop new strategies such as bottleneck strategies.

\section{Additional files}

\section{Additional file 1: Autocorrelogram of weekly malaria incidence. (JPG $46 \mathrm{~kb})$}

Additional file 2: First and second meteorological components derived from the Principal component analysis (PCA) of weekly meteorological variables. Rh max (Maximal relative humidity), Rh min (Minimal relative humidity), Rh ave. (Average relative humidity), Temp max (Maximal temperature), Temp min (Minimal temperature), Temp ave. (Average temperature), Rh max (Maximal relative humidity). (JPG 43 kb)

Additional file 3: Spatial hotspots according to the transmission periods (as described in Table 1) year from 2010 to 01-04 to 2014-12-31. Source: Burkina Faso, Base Nationale de Découpage du territoire (BNDT, 2006); shapefile downloaded from www.maplibrary.org. The map background (raster) is captured from https://www.openstreetmap.org/\#map=12/ 12.6228/-2.1622. Maps created by Toussaint Rouamba, 2018. (PDF 931 kb)

\section{Abbreviations \\ AIC: Akaike Information Criterion; aOR: Adjusted Odds Ratio; CCF: Cross Correlation Function; Cl: Confidence Interval; CISSE: Centre d'Information Sanitaire et de la Surveillance Epidémiologique; DGM: Direction Générale de la Météorologie; DSA: Demographic Surveillance Area; GEE: Generalized Estimating Equation; GPS: Global Positioning System coordinate; HAC: Hierarchical Ascendant Classification; HFP: Health Focal Points; MCA: Multiple Correspondence Analysis; NHD: Nanoro Health District; OR: Odds Ratio; PCA: Principal Component Analysis; PELT: Pruned Exact Linear Time; QIC: Quasi Akaike Information Criterion; RR: Relative Risk; SARIMA: Seasonal Autoregressive Integrated Moving Average; TLOH: Télégramme Lettre Official Hebdomendaire; WMO: World Meteorological Organization}

\section{Acknowledgements \\ We would like to thank everyone who supported this study directly or indirectly through fieldwork, data collection or analysis support. \\ The staff of health information and epidemiological surveillance centres of the Nanoro health districts. The meteorological service actors who collected and transmitted meteorological data. \\ We would like to thank professor Roch Giorgi and SESSTIM UMR1252 staff for their support. \\ The results have been partly presented (poster presentation) at the 10th European Congress on Tropical Medicine and International Health, 16-20 October 2017, Antwerp, Belgium [69].}

\section{Funding}

This work (Data analysis and manuscript redaction) has been carried out thanks to the support of the A*MIDEX grant ( $n^{\circ}$ ANR-11-IDEX-0001-02) funded by the French Government "Investissements d'Avenir program"). It was also supported by the French NGO Prospective\& Cooperation.

The main study 'Pharmacovigilance for artemisinin-based combination treatments in Africa' was supported WHO/TDR.

These institutions did not intervene in the study nor on the manuscript.

\section{Availability of data and materials}

The datasets used and/or analysed during the current study are available from the corresponding author on reasonable request. 


\section{Authors' contributions}

JG and TR designed the study protocol, performed statistical analysis and interpretation, drafted the manuscript; TR, SND, KD, AK, ER, SB, PY, MW, TH, EKO performed the data collection; TR, AG, YI, BO, SD participated to the data cleaning and statistical analysis; HT, KLS, FKS revised the article. All authors read and approved the final manuscript.

\section{Ethics approval and consent to participate}

All the socioeconomics and GPS coordinates data of households were obtained from Nanoro HDSS. The Nanoro DSA was created initially in the framework of a study entitled 'Pharmacovigilance for artemisinin-based combination treatments in Africa' (ClinicalTrials.gov Identifier: NCT01232530). This latter study was reviewed and approved by Centre Muraz Institutional Ethics Committee, the Burkina Faso National Ethics Committee and the World Health Organization (WHO) Ethical Review Committee. In this framework, a census of the population living in Nanoro department and around had been carried out after community consent was obtained.

The data presented in this work were extracted from the Nanoro HDSS data base, DGM data base, Nanoro health district TLHO, with the permission of the different Directors, Dr. Halidou Tinto, Dr. Ernest K. Ouédraogo and Dr. Seydou Barro. They have been made available for this study in an aggregated form so that the data request fulfils standards for transmission.

\section{Consent for publication}

Not applicable.

\section{Competing interests}

The authors declare that they have no competing interests.

\section{Publisher's Note}

Springer Nature remains neutral with regard to jurisdictional claims in published maps and institutional affiliations.

\section{Author details}

'Clinical Research Unit of Nanoro, Institute for Research in Health Sciences, National Center for Scientific and Technological Research, Nanoro, Burkina Faso. ${ }^{2}$ Aix Marseille Univ, IRD, INSERM, UMR1252 Sciences Economiques \& Sociales de la Santé \& Traitement de I'Information Médicale, Marseille, France. ${ }^{3}$ Center for Research in Epidemiology, Biostatistics and Clinical Research, School of Public Health, Université libre de Bruxelles (ULB), Brussels, Belgium. ${ }^{4}$ Embassy of Japan in the Republic of Guinea, Conakry, Guinea. ${ }^{5}$ Direction Générale de la Météorologie du Burkina Faso, Ouagadougou, Burkina Faso. ${ }^{6}$ Ecole des Hautes Etudes en Santé Publique, Rennes, France. ${ }^{7}$ MRTC, Malaria and Training Research Center - Ogobara Doumbo, Bamako, Mali. ${ }^{8}$ Direction Régionale de la Santé du Centre-Ouest, Ministère de la santé, Koudougou, Burkina Faso. ${ }^{9}$ Directorate of Health Information Systems, Ministry of Health, Ouagadougou, Burkina Faso. ${ }^{10}$ Aix Marseille Univ, APHM, INSERM, IRD, SESSTIM, Hop Timone, BioSTIC, Marseille, France.

\section{Received: 27 March 2018 Accepted: 19 February 2019}

\section{Published online: 28 February 2019}

\section{References}

1. Teklehaimanot HD, Lipsitch M, Teklehaimanot A, Schwartz J. Weather-based prediction of Plasmodium falciparum malaria in epidemic-prone regions of Ethiopia I. Patterns of lagged weather effects reflect biological mechanisms. Malar J. 2004;3:41. https://doi.org/10.1186/1475-2875-3-41.

2. Mouchet J, Faye O, Juivez J, Manguin S. Drought and malaria retreat in the Sahel, West Africa. Lancet. 1996;348:1735-6. https://doi.org/10.1016/S01406736(05)65860-6

3. Health Organization World. Global Technical Strategy for Malaria 2016-2030. Geneva: Global Malaria Programme; 2015. http://apps.who.int/iris/bitstream/ handle/10665/176712/9789241564991_eng.pdf;jsessionid= 66E6DA665C88369AF0BA3A99E8525283? sequence=1. Accessed 4 Sept 2018

4. Bousema T, Stresman G, Baidjoe AY, Bradley J, Knight P, Stone W, et al. The impact of hotspot-targeted interventions on malaria transmission in Rachuonyo South District in the Western Kenyan highlands: a clusterrandomized controlled trial. PLoS Med. 2016;13:e1001993. https://doi.org/10. 1371/journal.pmed.1001993.

5. Samadoulougou S, Maheu-Giroux M, Kirakoya-Samadoulougou F, De Keukeleire M, Castro MC, Robert A. Multilevel and geo-statistical modeling of malaria risk in children of Burkina Faso. Parasit Vectors. 2014;7:350. https://doi.org/10.1186/1756-3305-7-350.

6. Ouedraogo B, Inoue Y, Kambiré A, Sallah K, Dieng S, Tine R, et al. Spatio temporal dynamic of malaria in Ouagadougou, Burkina Faso, 2011-2015. Malar J. 2018;17:1-12. https://doi.org/10.1186/s12936-018-2280-y.

7. World Health Organisation. World Malaria Report: Geneva: World Health Organization; 2015. http://www.who.int/malaria/publications/world-malariareport-2015/en/

8. Tiono AB, Kangoye DT, Rehman AM, Kargougou DG, Kaboré Y, Diarra A, et al. Malaria incidence in children in south-West Burkina Faso: comparison of active and passive case detection methods. PLoS One. 2014;9:e86936. https://doi.org/10.1371/journal.pone.0086936.

9. Ministère de la Santé/Programme National de Lutte contre le Paludisme. Plan Stratégique National de Lutte Contre le Paludisme du Burkina Faso 2016-2020. Burkina Faso: Ministère de la Santé: 2016.

10. Ministère de la Santé/Direction Générale des Etudes et des Statistiques Sectorielles. Annuaire statistique 2016. Burkina Faso: Ministère de la Santé; 2017. http://www.sante.gov.bf/index.php?option=com_edocman\&task= document.viewdoc\&id=363\&ltemid=1123. Accessed 8 Sept 2017.

11. Ministère de la Santé/Programme National de Lutte contre le Paludisme. Directives Nationales pour la prise en charge du paludisme au Burkina Faso. Burkina Faso: Ministère de la Santé; 2017.

12. World Health Organization. T3: Test. Treat. Track initiative: WHO; 2016. http:// www.who.int/malaria/areas/test_treat_track/en/. Accessed 4 Sept 2018

13. SIG: Service d'Information du Gouvernement - Burkina Faso » COMPTE RENDU DU CONSEIL DES MINISTRES DU MERCREDI 02 MARS 2016. http:// www.sig.bf/2016/03/compte-rendu-du-conseil-des-ministres-du-mercredi02-mars-2016/. Accessed 24 Nov 2018.

14. Ministère de la Santé/Direction Générale des Etudes et des Statistiques Sectorielles. Annuaire statistique 2017. Burkina Faso: Ministère de la Santé; 2018. http://cns.bf/IMG/pdf/annuaire_ms_2017.pdf. Accessed 12 Sept 2018.

15. Ouédraogo LT, Somé IT, Diarra M, Guissou IP. Self-medication in the treatment of acute malaria: study based on users of private health drug stores in Ouagadougou, Burkina Faso. Bull Soc Pathol Exot. 2008;101:124-7 http://www.ncbi.nlm.nih.gov/pubmed/18543706. Accessed 8 Jul 2018.

16. Müller $\mathrm{O}$, Traoré $\mathrm{C}$, Becher $\mathrm{H}$, Kouyaté $\mathrm{B}$. Malaria morbidity, treatmentseeking behaviour, and mortality in a cohort of young children in rural Burkina Faso. Trop Med Int Health. 2003;8:290-6. https://doi.org/10.1046/j. 1365-3156.2003.01030.x.

17. Baragatti M, Fournet F, Henry M-C, Assi S, Ouedraogo H, Rogier C, et al. Social and environmental malaria risk factors in urban areas of Ouagadougou, Burkina Faso. Malar J. 2009;8:13. https://doi.org/10.1186/1475-2875-8-13.

18. Yamamoto S, Louis VR, Sié A, Sauerborn R. Household risk factors for clinical malaria in a semi-urban area of Burkina Faso: a case-control study. Trans R Soc Trop Med Hyg. 2010;104:61-5. https://doi.org/10.1016/j.trstmh. 2009.07.003.

19. Kreuels B, Kobbe R, Adjei S, Kreuzberg C, von Reden C, Bäter K, et al. Spatial variation of malaria incidence in young children from a geographically homogeneous area with high endemicity. J Infect Dis. 2008;197:85-93. https://doi.org/10.1086/524066

20. Bejon P, Williams TN, Liljander A, Noor AM, Wambua J, Ogada E, et al. Stable and unstable malaria hotspots in longitudinal cohort studies in Kenya. PLoS Med. 2010;7:e1000304. https://doi.org/10.1371/journal.pmed.1000304.

21. Midega JT, Smith DL, Olotu A, Mwangangi JM, Nzovu JG, Wambua J, et al. Wind direction and proximity to larval sites determines malaria risk in Kilifi District in Kenya. Nat Commun. 2012;3:674. https://doi.org/10.1038/ncomms1672.

22. Bousema T, Griffin JT, Sauerwein RW, Smith DL, Churcher TS, Takken W, et al. Hitting hotspots: spatial targeting of malaria for control and elimination. PLOS Med. 2012;9:e1001165. https://doi.org/10.1371/journal.pmed.1001165.

23. Landier J, Parker DM, Thu AM, Lwin KM, Delmas G, Nosten FH, et al. Effect of generalised access to early diagnosis and treatment and targeted mass drug administration on Plasmodium falciparum malaria in eastern Myanmar: an observational study of a regional elimination programme. Lancet. 2018; 391:1916-26. https://doi.org/10.1016/S0140-6736(18)30792-X.

24. Stresman GH, Mwesigwa J, Achan J, Giorgi E, Worwui A, Jawara M, et al. Do hotspots fuel malaria transmission : a village-scale spatio-temporal analysis of a 2-year cohort study in the Gambia. BMC Med. 2018;16:1-9. https://doi. org/10.1186/s12916-018-1141-4.

25. Gething PW, Patil AP, Smith DL, Guerra CA, Elyazar IR, Johnston GL, et al. A new world malaria map: Plasmodium falciparum endemicity in 2010. Malar J. 2011;10:378. https://doi.org/10.1186/1475-2875-10-378. 
26. Kleinschmidt I, Omumbo J, Brit O, Van De Giesen N, Sogoba N, Mensah NK, et al. An empirical malaria distribution map for West Africa. Trop Med Int Heal. 2001;6:779-86. https://doi.org/10.1046/j.1365-3156.2001.00790.x.

27. Gaudart J, Poudiougou B, Dicko A, Ranque S, Toure O, Sagara I, et al. Spacetime clustering of childhood malaria at the household level: a dynamic cohort in a Mali village. BMC Public Health. 2006;6:286. https://doi.org/10. 1186/1471-2458-6-286

28. Yeshiwondim AK, Gopal S, Hailemariam AT, Dengela DO, Patel HP. Spatial analysis of malaria incidence at the village level in areas with unstable transmission in Ethiopia. Int J Health Geogr. 2009;8:5. https://doi.org/10. 1186/1476-072X-8-5

29. Wangdi K, Canavati SE, Ngo TD, Tran LK, Nguyen TM, Tran DT, et al. Analysis of clinical malaria disease patterns and trends in Vietnam 2009-2015. Malar J. 2018;17:332. https://doi.org/10.1186/s12936-018-2478-z.

30. Parker DM, Tripura R, Peto TJ, Maude RJ, Nguon C, Chalk J, et al. A multilevel spatial analysis of clinical malaria and subclinical Plasmodium infections in Pailin Province, Cambodia. Heliyon. 2017;3:e00447. https://doi. org/10.1016/j.heliyon.2017.e00447.

31. Yé Y, Kyobutungi C, Louis VR, Sauerborn R. Micro-epidemiology of Plasmodium falciparum malaria: is there any difference in transmission risk between neighbouring villages? Malar J. 2007;6:46. https://doi.org/10.1186/1475-2875-6-46.

32. Pierrat $C$. Risque palustre : appréhender la vulnérabilité des individus à l'échelle locale (Sud du Bénin). VertigO - la Rev électronique en Sci l'environnement. 2012;11:1-22. https://doi.org/10.4000/vertigo.11549.

33. Patz JA, Strzepek K, Lele S, Hedden M, Greene S, Noden B, et al. Predicting key malaria transmission factors, biting and entomological inoculation rates, using modelled soil moisture in Kenya. Trop Med Int Heal TM IH. 1998;3: 818-27. https://doi.org/10.1046/j.1365-3156.1998.00309.x.

34. Diboulo E, Sié A, Vounatsou P. Assessing the effects of malaria interventions on the geographical distribution of parasitaemia risk in Burkina Faso. Malar J. 2016;15:228. https://doi.org/10.1186/s12936-016-1282-x.

35. Yé Y, Hoshen M, Kyobutungi C, Louis VR, Sauerborn R. Local scale prediction of plasmodium falciparum malaria transmission in an endemic region using temperature and rainfall. Glob Health Action. 2009;2. https://doi.org/10. 3402/gha.v2i0.1923.

36. Derra K, Rouamba E, Kazienga A, Ouedraogo S, Tahita MC, Sorgho H, et al. Profile: Nanoro health and demographic surveillance system. Int J Epidemiol. 2012:41:1293-301. https://doi.org/10.1093/ije/dys159.

37. Institut National de la Statistique et de la Démographie. Enquête sur les Indicateurs du Paludisme au Burkina Faso (EIPBF). Ouagadougou: INSD; 2014. https://dhsprogram.com/pubs/pdf/MIS19/MIS19.pdf

38. Tinto $H$, Valea I, Sorgho $H$, Tahita $M$, Traore $M$, Bihoun B, et al. The impact of clinical research activities on communities in rural Africa: the development of the clinical research unit of Nanoro (CRUN) in Burkina Faso. Malar J. 2014 13:113. https://doi.org/10.1186/1475-2875-13-113.

39. Diello P, Paturel JE, Mahe G. Approche d'identification d'un réseau climatique pour le suivi du climat au Burkina Faso. Sud Sci Technol. 2003;10: 18-25. http://hdl.handle.net/2042/30343

40. Bayazit M, Önöz B. To prewhiten or not to prewhiten in trend analysis? Hydrol Sci J. 2007:52:611-24. https://doi.org/10.1623/hysj.52.4.611.

41. Onoz Bayazit MB. The power of statistical test for trend detection. Turkish J Eng Environ Sci. 2003;27:247-51 http://journals.tubitak.gov.tr/engineering/ issues/muh-03-27-4/muh-27-4-5-0206-6.pdf.

42. Box GEP, Jenkins GM. Time Series Analysis: Forecasting and Control. In: Holden-Day. San Francisco: Holden-Day; 1976. p. 575.

43. Jolliffe I. Principal component analysis. 2nd ed. New York: Springer-Verlag; 2002. https://trove.nla.gov.au/version/180765988

44. Killick R, Eckley IA. changepoint: An R Package for Changepoint Analysis. J Stat Softw. 2014;58:1-19. https://doi.org/10.18637/jss.v058.i03.

45. Killick R, Fearnhead P, Eckley IA. Optimal detection of changepoints with a linear computational cost. J Am Stat Assoc. 2012;107:1590-8. https://doi.org/ 10.1080/01621459.2012.737745

46. Zhang NR, Siegmund DO. A modified Bayes information criterion with applications to the analysis of comparative genomic hybridization data. Biometrics. 2007;63:22-32. https://doi.org/10.1111/j.1541-0420.2006.00662.x.

47. Kulldorff M. A spatial scan statistic. Commun Stat Theory Methods. 1997; 26:1481-96 https://www.satscan.org/papers/k-cstm1997.pdf. Accessed 15 Sept 2018.

48. Guttmann A, Ouchchane L, Li X, Perthus I, Gaudart J, Demongeot J, et al. Performance map of a cluster detection test using extended power. Int J Health Geogr. 2013;12:47. https://doi.org/10.1186/1476-072X-12-47.
49. Guttmann A, Li X, Feschet F, Gaudart J, Demongeot J, Boire J-Y, et al. Cluster detection tests in spatial epidemiology: a global Indicator for performance assessment. PLoS One. 2015;10:e0130594. https://doi.org/10. 1371/journal.pone.0130594.

50. Ludovic L, Alain M, Marie P. Statistique exploratoire multidimensionnelle. Paris: Dunod; 1995.

51. Pan W. Akaike's information criterion in generalized estimating equations. Biometrics. 2001;57:120-5. https://doi.org/10.1111/j.0006-341X.2001.00120.x

52. Lucius R, Loos-Frank B. Biologie von Parasiten. 2nd ed. Berlin, Heidelberg: Springer Verlag; 2008.

53. Martens W, Niessen L, Rotmans J, Jetten TH, McMichael J. Climate change and vector-borne disease: a global modelling perspective. Glob Env Chang. 1995:5:195-209. https://doi.org/10.1016/0959-3780(95)00051-O.

54. Centers for Disease Control and Prevention. Malaria - About Malaria Biology. 2018. https://www.cdc.gov/malaria/about/biology/index.html. Accessed 6 Sept 2018.

55. Hurtado LA, Calzada JE, Rigg CA, Castillo M, Chaves LF. Climatic fluctuations and malaria transmission dynamics, prior to elimination, in Guna Yala, República de Panamá. Malar J. 2018;17:85. https://doi.org/10.1186/s12936-018-2235-3.

56. Krefis AC, Schwarz NG, Krüger A, Fobil J, Nkrumah B, Acquah S, et al. Modeling the relationship between precipitation and malaria incidence in children from a holoendemic area in Ghana. Am J Trop Med Hyg. 2011;84 285-91. https://doi.org/10.4269/ajtmh.2011.10-0381.

57. Midekisa A, Senay G, Henebry GM, Semuniguse P, Wimberly MC. Remote sensing-based time series models for malaria early warning in the highlands of Ethiopia. Malar J. 2012;11:165. https://doi.org/10.1186/1475-2875-11-165.

58. Bi P, Tong S, Donald K, Parton KA, Ni J. Climatic variables and transmission of malaria: a 12-year data analysis in Shuchen County, China. Public Health Rep. 2003;118:65-71. https://doi.org/10.1016/S0033-3549(04)50218-2.

59. Wu Y, Qiao Z, Wang N, Yu H, Feng Z, Li X, et al. Describing interaction effect between lagged rainfalls on malaria: an epidemiological study in southWest China. Malar J. 2017;16:53. https://doi.org/10.1186/s12936-017-1706-2.

60. Coulibaly D, Travassos MA, Tolo Y, Laurens MB, Kone AK, Traore K, et al. Spatio-temporal dynamics of asymptomatic malaria: bridging the gap between annual malaria resurgences in a Sahelian environment. Am J Trop Med Hyg. 2017;97:1761-9. https://doi.org/10.4269/ajtmh.17-0074.

61. Pascual M, Cazelles B, Bouma MJ, Chaves LF, Koelle K. Shifting patterns: malaria dynamics and rainfall variability in an African highland. Proc Biol Sci. 2008;275:123-32. https://doi.org/10.1098/rspb.2007.1068.

62. Van Der Hoek W, Konradsen F, Perera D, Amerasinghe PH, Amerasinghe FP. Correlation between rainfall and malaria in the dry zone of Sri Lanka. Ann Trop Med Parasitol. 1997;91:945-9. https://doi.org/10.1080/00034989760347.

63. Singh N, Sharma VP. Patterns of rainfall and malaria in Madhya Pradesh, Central India. Ann Trop Med Parasitol. 2002;96:349-59. https://doi.org/10. 1179/000349802125001113.

64. Kabaria CW, Gilbert M, Noor AM, Snow RW, Linard C. The impact of urbanization and population density on childhood Plasmodium falciparum parasite prevalence rates in Africa. Malar J. 2017;16:49. https://doi.org/10. 1186/s12936-017-1694-2.

65. Siraj AS, Bouma MJ, Santos-Vega M, Yeshiwondim AK, Rothman DS, Yadeta $D$, et al. Temperature and population density determine reservoir regions of seasonal persistence in highland malaria. Proc Biol Sci. 2015;282:20151383. https://doi.org/10.1098/rspb.2015.1383.

66. Bejon P, Williams TN, Nyundo C, Hay SI, Benz D, Gething PW, et al. A microepidemiological analysis of febrile malaria in coastal Kenya showing hotspots within hotspots. Elife. 2014;3:e02130. https://doi.org/10.7554/eLife.02130.

67. Wang S-J, Lengeler C, Smith TA, Vounatsou P, Diadie DA, Pritroipa X, et al. Rapid urban malaria appraisal (RUMA) I: epidemiology of urban malaria in Ouagadougou. Malar J. 2005;16:1-16. https://doi.org/10.1186/1475-2875-4-43.

68. Yaméogo TM, Kyelem CG, Bamba S, Savadogo LB, Sombié I, Traoré AZ, et al. Chemin de soin des cas présomptifs de paludisme admis dans un hôpital de district au Burkina Faso. Med Sante Trop. 2014;24:301-6. https://doi.org/ 10.1684/mst.2014.0368

69. Rouamba T, Nakanabo-Diallo S, Derra K, Rouamba E, Kankoe S, Yaka P, et al. Environmental characteristics and evolution of malaria hotspots in a rural area, Burkina Faso. In: 10th European Congress on Tropical Medicine and International Health. Antwerp: Tropical Medicine and International Health; 2017. p. 224. https://onlinelibrary.wiley.com/doi/abs/10.1111/tmi.12979. Accessed 31 Aug 2018. 